\title{
The specificities of deformations and failures of highly stressed hard rock massifs
}

\author{
Anatolii Kozyrev ${ }^{1}$, Eduard Kasparyan ${ }^{1}$, Iuliia Fedotova ${ }^{2}$, and Nikolay Kuznetcov ${ }^{1 *}$ \\ ${ }^{1}$ MI KSC RAS, Laboratory of Geomechanics, 184209 Fersman st., 24, Apatity, Russia \\ ${ }^{2}$ MI FEB RAS, Laboratory of the digital methods research of natural and technical systems, 680000 \\ Turgeneva st., 51, Khabarovsk, Russia
}

\begin{abstract}
According to modern concepts, the state of highly stressed hard rock massifs is mostly caused by the effect of gravitational-tectonic stress fields. At that, a probability of brittle rock failure in a dynamic form is very high. Such failures are always accompanied by the significant energy release accumulated during the deformation process. Based on the experimental studies of deformation and failure processes in various types of rock samples from the Kola Peninsula deposits, we have proposed the criteria for classifying rocks as prone to rock bursts. The information for assessing the rock proneness to dynamic failures can be obtained by analysing the strain curve at the pre-peak section when tested on the ordinary presses and testing devices according to the standard methods. If we study the processes of rocks' deformation and energy accumulation under the triaxial loading mode, we can establish the parameters for the occurrence of dynamic failure of rocks. This, in turn, will allow identifying the conditions of such failure in the investigated rocks for a specific mining-engineering situation and, thereby, coming to a scientifically-based prediction of the rocks' proneness to dynamic rock pressure occurrences.
\end{abstract}

\section{Introduction}

Intensive and large-scale activity of mining enterprises in the underground mining of rockburst-hazardous deep seated ore deposits affects the change in mechanical stresses in the upper part of the earth's crust. These changes are accompanied by irreversible geomechanical processes and dangerous geodynamic phenomena (rockburst and tectonic bumps, mining induced seismicity). The problem to predict of the dangerous geodynamic phenomena is an urgent and complex task, due to many factors and causes of their manifestation, geological and technological conditions of mining.

The results of numerous direct measurements of natural stress field's components indicate the stress state of high-strength hard rock massifs to be mostly characterized by the action of gravitational-tectonic stress fields [1,2]. Apparently, such stress fields are more typical for high-strength rock massifs.

* Corresponding author: nikavalon@mail.ru 
In hard rock massifs under the action of gravitational-tectonic natural stress fields, the rock failure occurs often in the dynamic mode with the energy release (often in significant amount) accumulated during previous deformation.

This is the cause of numerous seismic events which are constantly registered in the hard rock massifs and occur in the mines as rock bursts with different intensity.

The studies of deformations and failures in the highly-stressed hard rock massifs and problems of prevention and prediction of rock bursts while developing mineral deposits are very relevant.

The rock burst prediction and prevention problem is no more than 300 years. During this period of time lots of studies have been carried out and a lot of actual material has been accumulated. The basic factors defining the conditions of dynamic failure occurrence have been revealed. Also various physical mechanisms of these dynamic failures have been offered.

By now researchers have established the main reasons and conditions for a dynamic rock failure (as well as for all solid materials), when a failure is accompanied by the release of energy accumulated in the process of loading in very short periods of time and, sometimes, in very significant quantities. Almost all of the researchers agree that there are two reasons for this.

The first reason is specific properties of rocks, which are manifested in rock ability to elastically deform almost to the point of failure and, therefore, accumulate large amounts of potential elastic energy. When reaching the strength threshold of the volume considered, the energy is almost instantly emitted in different forms, in particular, in the form of mechanical movements of material fragments and various types of radiation.

The second reason is special conditions of the rock mass stress state.

In all of the proposed mechanisms of rock failure development in the dynamic form these two main reasons are always considered in one form or another. Based on them, dynamic rock pressure conditions and rockburst hazard criteria are formulated. At that, the state of knowledge of these reasons is quite different.

\section{The method for estimating the rock proneness to a dynamic failure}

By now the properties of rocks have been studied in detail. The methods for determining the parameters of mechanical properties have been developed, in particular, the strength characteristics under various loading modes. A wide range of laboratory test devices is available. Many of these devices are manufactured under industrial conditions.

Also, the methods have been developed for estimating the rock ability to a dynamic failure [3-5]. At that, most of the methods require the use of special test devices with increased stiffness, which are unique or produced by foreign manufactures.

The methods proposed, despite their efficiency, should be recognized only as methodical ones, because they do not fully reflect the failure mechanism in the real conditions of rock massifs. First of all, it concerns the ability of tested rocks to accumulate energy during deformation before a failure.

The Mining Institute of the Kola Science Centre RAS has developed a method for estimating the rock proneness to a dynamic failure (rockburst hazard) based on the analysis of pre-peak deformation curves obtained under the tests on conventional standard test devices [6].

As a result of tests of various rock types from the Kola Peninsula deposits it was established that the deformation graphs (Fig. 1) can have a concave and convex shape relative to a straight line (a dotted line on Fig. 1), which characterizes the perfectly elastic deformation of the material. 


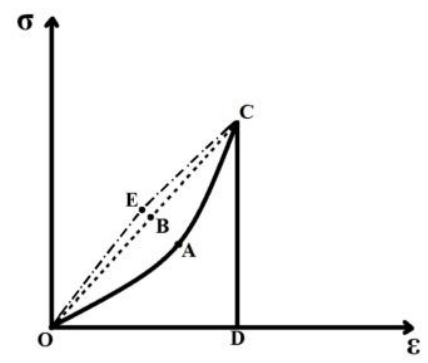

Fig. 1. The graphs of hard rock deformation established by the test results: $\sigma$ - normal stress, $\varepsilon$ relative longitudinal strain.

In this case (Fig. 1) OBC is a conditional line of perfectly elastic deformation, OAC is a graph of inelastic deformation, OEC is a special case of deformation with excess of elastic energy. Point C - unconfined compression strength; point D - longitudinal strain value corresponded to the unconfined compression strength.

The value of deformation energy of rocks up to the unconfined compression strength $(\mathrm{Wr})$ is defined as the value of a certain integral:

$$
W_{r}=\int_{O}^{D} \sigma(\varepsilon) d \varepsilon
$$

The energy value under perfectly elastic deformation $\left(W_{p e}\right)$ is determined as the area of the triangle $\mathrm{OBCD}$ :

$$
W_{p e}=\mathrm{SOBCD}=(\mathrm{OD} \cdot \mathrm{DC}) / 2
$$

When we get a concave rock deformation curve as a result of the tests, it means that the strain energy is not accumulated in a sample but is realized in the form of plastic deformations during the loading. At that, the strain energy for all time periods remains less than the energy value corresponding to the perfectly elastic deformation.

When the deformation curve is convex, the elastic energy is accumulated in a sample and for all time periods exceeds the energy value corresponding to the perfectly elastic deformation.

According to the study results, two specified different deformation modes for the tested rock types have been revealed and a criterion of rock assignment to various categories on a degree of proneness to a dynamic or static failure has been defined.

In particular, if a real strain energy value is less than a conditionally calculated perfectly elastic energy by a value greater than $10 \%$, the rock can be confidently attributed to the type of rocks prone to a static failure only. The dynamic failures are unlikely. Therefore such rocks should be categorized as "non-hazardous rocks by rock bursts".

In all other cases, when the difference between real strain energy values is less than conditionally calculated perfectly elastic energy by a value of up to $10 \%$ or is equal to zero, as well as, if the values of real energy exceed the values of perfectly elasticity, the rocks are prone to a dynamic failure. Therefore, the rock massifs, including such rocks, should be attributed to the rockburst-prone and rockburst-hazardous.

According to the results presented in Table 1, all the tested rocks, except for calcite carbonatite (the Kovdor deposit), are prone to a dynamic failure. At that, based on a value of real accumulated energy $\left(W_{r}=0.2762 \mathrm{MJ} / \mathrm{m}^{3}\right)$, the most rockburst hazardous rock is massive juvite (apatite-nepheline deposits). This conclusion is confirmed by the test results carried out in accordance with the currently accepted methods, as well as by the work experience of KB JSC "Apatit" mines. 
Table 1. The results of hard rock tests.

\begin{tabular}{|c|c|c|c|c|c|c|c|c|}
\hline \multirow[t]{2}{*}{ Type of rocks } & \multicolumn{2}{|c|}{$\begin{array}{l}\text { Strength of } \\
\text { rocks }\end{array}$} & \multirow{2}{*}{$\begin{array}{c}\text { Elastic } \\
\text { modulus } \\
\mathrm{MPa} \cdot 10^{4}\end{array}$} & \multirow{2}{*}{$\begin{array}{l}\text { Poisson } \\
\text { ratio }\end{array}$} & \multirow{2}{*}{$\begin{array}{c}\text { Perfectly } \\
\text { elastic } \\
\text { specific } \\
\text { strain } \\
\text { energy } \\
W_{\text {pe }} \\
\mathrm{MJ} / \mathrm{m}^{3} \\
\end{array}$} & \multirow{2}{*}{$\begin{array}{c}\text { Real } \\
\text { specific } \\
\text { strain } \\
\text { energy } \\
W_{r}, \\
\mathrm{MJ} / \mathbf{m}^{3}\end{array}$} & \multicolumn{2}{|c|}{$\begin{array}{c}\text { The } \\
\text { difference } \\
\text { between } \\
W_{\text {pe }} \text { и } W_{r} \\
\end{array}$} \\
\hline & $\begin{array}{l}\text { UCS, } \\
\text { MPa }\end{array}$ & $\begin{array}{l}\text { UTS, } \\
\text { MPa }\end{array}$ & & & & & $\mathbf{M J} / \mathbf{m}^{3}$ & $\%$ \\
\hline \multicolumn{9}{|c|}{ Apatite-nepheline deposits } \\
\hline \multirow{4}{*}{$\begin{array}{c}\text { Trachytoid } \\
\text { ijolite }\end{array}$} & \multirow{4}{*}{230} & \multirow{4}{*}{13.1} & \multirow{4}{*}{8.89} & \multirow{4}{*}{0.22} & 0.1401 & 0.1298 & 0.0103 & 7 \\
\hline & & & & & 0.2923 & 0.2619 & 0.0304 & 10 \\
\hline & & & & & 0.1723 & 0.1650 & 0.0072 & 4 \\
\hline & & & & & 0.2016 & 0.1856 & 0.0160 & $\mathbf{8}^{\dagger}$ \\
\hline \multirow{5}{*}{$\begin{array}{l}\text { Inequigranular } \\
\text { urtite with } \\
\text { aegirine }\end{array}$} & \multirow{5}{*}{200} & \multirow{5}{*}{9.5} & \multirow{5}{*}{7.87} & \multirow{5}{*}{0.26} & 0.2543 & 0.2430 & 0.0112 & 4 \\
\hline & & & & & 0.2281 & 0.2389 & -0.0107 & -5 \\
\hline & & & & & 0.2422 & 0.2316 & 0.0105 & 4 \\
\hline & & & & & 0.2347 & 0.2370 & -0.0024 & -1 \\
\hline & & & & & 0.2398 & 0.2376 & 0.0022 & 1 \\
\hline \multirow{5}{*}{$\begin{array}{c}\text { Medium- } \\
\text { granular } \\
\text { massive urtite }\end{array}$} & \multirow{5}{*}{175} & \multirow{5}{*}{9.3} & \multirow{5}{*}{7.22} & & 0.1426 & 0.1426 & 0.0000 & 0 \\
\hline & & & & & 0.1591 & 0.1580 & 0.0011 & 1 \\
\hline & & & & 0.28 & 0.2015 & 0.1996 & 0.0019 & 1 \\
\hline & & & & & 0.2010 & 0.2030 & -0.0020 & -1 \\
\hline & & & & & 0.1760 & 0.1758 & 0.0002 & $\mathbf{0}$ \\
\hline & & & & & 0.1073 & 0.0960 & 0.0113 & 11 \\
\hline & & & & & 0.1922 & 0.1872 & 0.0051 & 3 \\
\hline Pegmatord & 155 & 9,1 & 7.56 & 0.25 & 0.1260 & 0.1249 & 0.0011 & 1 \\
\hline & & & & & 0.1191 & 0.1215 & -0.0025 & -2 \\
\hline & & & & & 0.1361 & 0.1324 & 0.0037 & 3 \\
\hline & & & & & 0.2049 & 0.2112 & -0.0064 & -3 \\
\hline & & & & & 0.2223 & 0.2155 & 0.0067 & 3 \\
\hline Mascive iuvite & 170 & 107 & 603 & 026 & 0.3962 & 0.4102 & -0.0141 & -4 \\
\hline iviassive juvile & $1 / 0$ & 10.1 & 0.95 & 0.20 & 0.3597 & 0.3579 & 0.0018 & 1 \\
\hline & & & & & 0.1901 & 0.1860 & 0.0041 & 2 \\
\hline & & & & & 0.2746 & 0.2762 & -0.0016 & $\mathbf{0}$ \\
\hline & & & & & 0.1760 & 0.1626 & 0.0135 & 8 \\
\hline & & & & & 0.1602 & 0.1424 & 0.0178 & 11 \\
\hline Spotted-striped & 114 & 66 & 615 & 020 & 0.0965 & 0.0896 & 0.0069 & 7 \\
\hline $\begin{array}{l}\text { apatite- } \\
\text { nepheline ore }\end{array}$ & 114 & 0.0 & 0.15 & 0.20 & 0.0777 & 0.0680 & 0.0097 & 12 \\
\hline & & & & & 0.0660 & 0.0616 & 0.0044 & 7 \\
\hline & & & & & 0.1153 & 0.1048 & 0.0105 & 9 \\
\hline & & & & & 0.1430 & 0.1197 & 0.0233 & 16 \\
\hline & & & & & 0.1554 & 0.1507 & 0.0047 & 3 \\
\hline $\begin{array}{l}\text { Lenticular- } \\
\text { strined anatite- }\end{array}$ & 145 & 52 & 656 & 020 & 0.1122 & 0.1120 & 0.0003 & 0 \\
\hline striped apatile- & 145 & 5.2 & 0.50 & 0.20 & 0.1746 & 0.1642 & 0.0104 & 6 \\
\hline & & & & & 0.0860 & 0.0763 & 0.0097 & 11 \\
\hline & & & & & 0.1343 & 0.1246 & 0.0097 & 7 \\
\hline & & Rocks & the Zair & drovsky & n ore regi & & & \\
\hline & & & & & 0.1451 & 0.1415 & 0.0036 & 2 \\
\hline & & & & & 0.0946 & 0.0927 & 0.0019 & 2 \\
\hline Grey gneiss & 140 & 10.1 & 6.86 & 0.20 & 0.1795 & 0.1826 & -0.0032 & -2 \\
\hline & & & & & 0.0840 & 0.0769 & 0.0071 & 8 \\
\hline
\end{tabular}

$\dagger$ bold indicates average values 


\begin{tabular}{|c|c|c|c|c|c|c|c|c|}
\hline & & & & & 0.1258 & 0.1234 & 0.0024 & 2 \\
\hline \multirow{5}{*}{$\begin{array}{c}\text { Grey } \\
\text { leucocratic } \\
\text { gneiss }\end{array}$} & \multirow{5}{*}{190} & \multirow{5}{*}{11.6} & \multirow{5}{*}{7.56} & \multirow{5}{*}{0.17} & 0.1366 & 0.1275 & 0.0090 & 7 \\
\hline & & & & & 0.1832 & 0.1642 & 0.0189 & 10 \\
\hline & & & & & 0.0845 & 0.0770 & 0.0076 & 9 \\
\hline & & & & & 0.0877 & 0.0741 & 0.0137 & 16 \\
\hline & & & & & $\mathbf{0 . 1 2 3 0}$ & 0.1107 & 0.0123 & 10 \\
\hline \multicolumn{9}{|c|}{ Zhdanovskoe copper-nickel deposit } \\
\hline \multirow{7}{*}{ Gabbro } & \multirow{7}{*}{99} & \multirow{7}{*}{18.0} & \multirow{7}{*}{6.47} & \multirow{7}{*}{0.28} & 0.1434 & 0.1472 & -0.0038 & -3 \\
\hline & & & & & 0.2138 & 0.2282 & -0.0144 & -7 \\
\hline & & & & & 0.1970 & 0.1985 & -0.0015 & -1 \\
\hline & & & & & 0.2431 & 0.2549 & -0.0117 & -5 \\
\hline & & & & & 0.3990 & 0.4069 & -0.0079 & -2 \\
\hline & & & & & 0.3059 & 0.3208 & -0.0149 & -5 \\
\hline & & & & & 0.2504 & 0.2594 & -0.0090 & -4 \\
\hline \multirow{4}{*}{ Diabase } & \multirow{4}{*}{76} & \multirow{4}{*}{15.3} & \multirow{4}{*}{6.66} & \multirow{4}{*}{0.27} & 0.2250 & 0.2394 & -0.0144 & -6 \\
\hline & & & & & 0.0813 & 0.0838 & -0.0025 & -3 \\
\hline & & & & & 0.1926 & 0.2016 & -0.0091 & -5 \\
\hline & & & & & 0.1663 & 0.1749 & -0.0087 & -5 \\
\hline \multicolumn{9}{|c|}{ Kovdor magnetite-apatite-baddeleite deposit } \\
\hline \multirow{6}{*}{$\begin{array}{c}\text { Calcite } \\
\text { carbonatite } \\
\text { with ijolite } \\
\text { inclusions }\end{array}$} & \multirow{6}{*}{80} & \multirow{6}{*}{4.6} & \multirow{6}{*}{4.88} & \multirow{6}{*}{0.22} & 0.0066 & 0.0054 & 0.0012 & 18 \\
\hline & & & & & 0.0113 & 0.0079 & 0.0033 & 30 \\
\hline & & & & & 0.0171 & 0.0129 & 0.0042 & 25 \\
\hline & & & & & 0.0169 & 0.0125 & 0.0044 & 26 \\
\hline & & & & & 0.0169 & 0.0109 & 0.0060 & 35 \\
\hline & & & & & 0.0137 & 0.0099 & 0.0038 & 28 \\
\hline \multirow{6}{*}{$\begin{array}{c}\text { Apatite- } \\
\text { carbonate- } \\
\text { magnetite ore }\end{array}$} & \multirow{6}{*}{130} & \multirow{6}{*}{9.3} & \multirow{6}{*}{13.03} & \multirow{6}{*}{0.26} & 0.0502 & 0.0409 & 0.0012 & 2 \\
\hline & & & & & 0.0470 & 0.0469 & 0.0001 & 0 \\
\hline & & & & & 0.0412 & 0.0408 & 0.0004 & 1 \\
\hline & & & & & 0.0405 & 0.0396 & 0.0009 & 2 \\
\hline & & & & & 0.0432 & 0.0404 & 0.0028 & 6 \\
\hline & & & & & 0.0444 & 0.0433 & 0.0011 & 2 \\
\hline
\end{tabular}

It should be noted that the established criteria of dynamic failures of rocks belong to the worst case - uniaxial loading, when the heterogeneity of the stress field is maximum because all the tensor components, except one, are zero. It is quite obvious that at other relations of the stress tensor components (in the conditions of volumetric stress field which is typical for the internal regions of rock massifs) the type of deformation curves will be different and the criteria should be also different. The determination of dynamic rock failure criteria for volumetric rock loading is an urgent task of the nearest studies.

\section{The specificity of gravitational-tectonic stress fields}

The second direction of the problem considered - a real picture of stress distribution in specific rock mass areas and taking into account the degree of stresses while predicting a dynamic rock failure and, consequently, seismic events (including rockburst hazard) - has been developed to a lesser extent by now.

A distinctive feature of the tensor of gravitational-tectonic stress field is the presence of horizontal components, one of which is usually significantly (in several times) higher than a vertical component caused by gravity. The other horizontal component is usually minimal.

Such a structure of gravitational-tectonic fields of natural stresses predetermines a very high degree of heterogeneity of stresses in the rock massifs. As is known, the higher the degree of heterogeneity of the effective stresses, the higher the probability of a rock failure. 
It should be noted that in many cases the absolute values of effective stresses of the gravitational-tectonic fields may not be very large but the heterogeneity of the stress fields is very high. This fact can explain the numerous cases of failures in the near-surface areas of rock mass, near the geological disturbances, faults, in the pillars, in the locks of consoles of collapsing rocks, in quarries, etc.

This is most clearly illustrated by the data given in [7]. This work provides documented information that the upper levels of the Khibiny apatite-nepheline mines are characterized by higher seismicity and a greater number of powerful seismic events compared to deeper levels. The recorded values of the stress field components on the upper levels are lower than the values on the lower levels, but the heterogeneity of the stress field, i.e. the difference between the stress components, is higher.

Meanwhile, less attention is given to the higher degree of heterogeneity of the gravitational-tectonic stress fields (as compared to the gravitational field). Also the heterogeneity of the stress field in the calculation methods of estimating the conditions of rock failure is rarely taken into account. The comparisons of absolute stress values with the corresponding rock strength parameters are most often used as the criteria of rock failure.

It should be noted that the specified difference in the components of a gravitationaltectonic stress field causes a high degree of heterogeneity at each point in the rock mass. But from the point of view of prediction and prevention of dynamic rock failures, the heterogeneity of the stress fields in separate structural macroblocks of the rock mass is even more important.

With the development of geomechanics and the accumulation of experimental and insitu data when descripting a general structure of natural stress fields in rock mass, there is a steady tendency of gradual transition from the hypotheses of homogeneous stress fields in the rock mass caused by gravity [8] or by jointly gravitational and tectonic forces [2] to the ideas of the hierarchy of stress fields [9] in full accordance with the hierarchical-blocked conceptualization of the rock massif's structure.

Fig. 2 shows the scheme of ranking of natural stress fields in the rock mass.

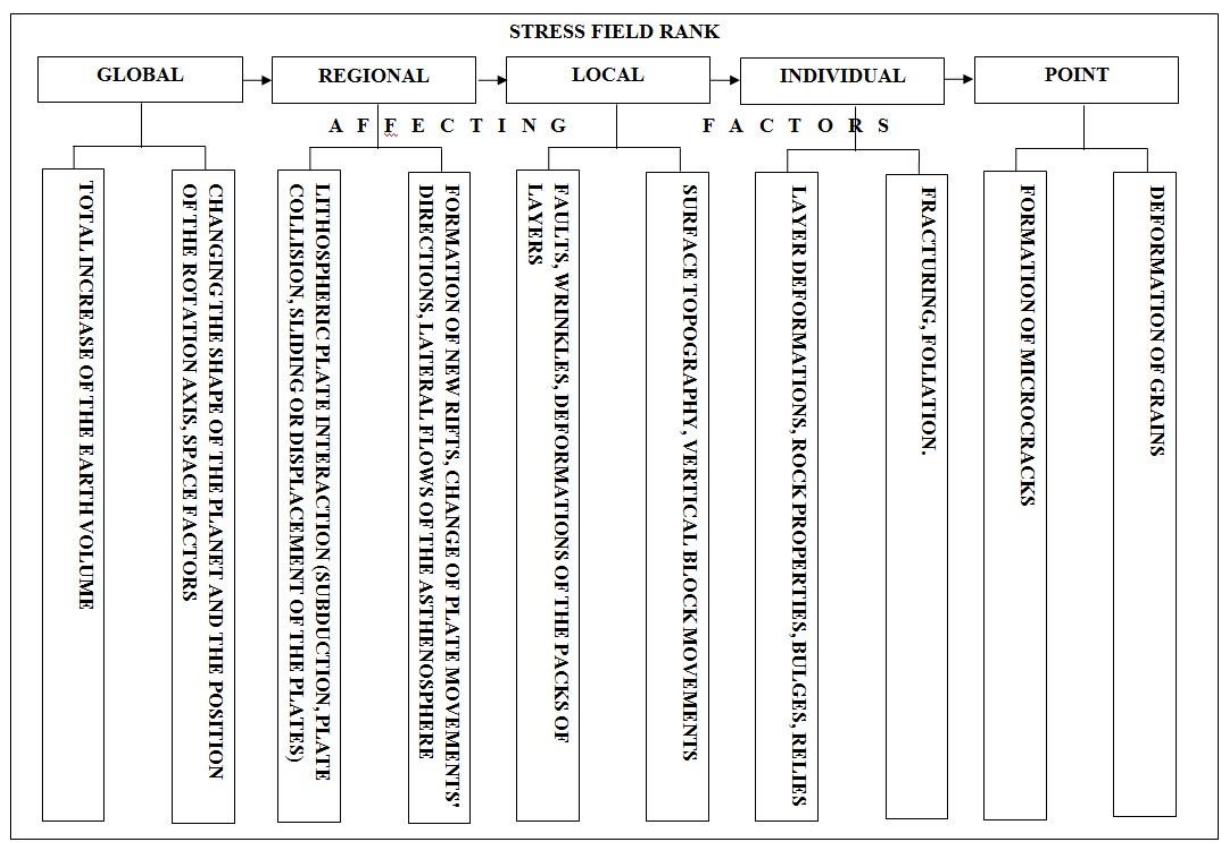

Fig. 2. The scheme of ranking of natural stress fields in the rock mass 
The global stress fields are the result of occurrence of planetary tectonic processes. The regional scale of the stress fields is determined by the state of large areas of the Earth's crust (with linear sizes up to tens of thousands of kilometres), in particular, lithospheric plates.

Local and individual stress fields are typical for blocks of a substantially smaller structural level (with sizes from the first kilometres to tens of meters), contoured by structural elements of an appropriate rank which can be represented by faults, geological disturbances, contacts of ore bodies with the host rocks, large block fractures, etc. The local and individual stress fields in the scale of mining allotments of mining enterprises are of main interest from the point of view of tectonic processes management under development of mineral deposits.

Point fields characterize the stress state in the smallest volumes of the rock massifs at the level of contacts of separate mineral grains and micro-fractures. These fields are responsible for mass seismic occurrences in the rock massifs. On the basis of special studies it has been established that a failure in the hierarchical-blocked medium begins at the level of the highest ranks of structural discontinuities of the rock mass [9].

The main feature of hierarchical distributions of any characteristics is a clear dependence between the parameters of considered processes and the sizes of areas where these processes are occurred. This fully corresponds to the hierarchy of the stress fields. The parameters of separate ranks of stress fields differ significantly among themselves (apparently, the general trend is a gradual decrease in the absolute values of the effective stresses with the gradual transition from the point fields to the global one) and cannot be used without a clear indication of the size of the corresponding structural blocks. On this basis, it is not quite correct to make conclusions about the parameters of the stress fields, for example, according to the data of doorstopper measurement method for the volumes of rock massifs comparable to the usual volumes of mining blocks in modern mining methods.

From the point of representations about the hierarchy of stress fields, the data obtained recently by various researchers about the mosaic of stress fields in real rock massifs [10$12]$, about the anomalies of the stress state of large structural discontinuities - faults [13,14] and other features of stress fields in specific conditions of rock massifs of mineral deposits developed become quite understandable.

The rank of structural discontinuities involved in the deformation process and subsequent failures determines the amount of energy accumulated under deformation and released under failure. In seismology the clear (but empirical) relations between the value of energy radiated and the size of the resulting discontinuities have been determined long ago $[15,16]$.

For example, for the conditions of the Kola Peninsula apatite-nepheline deposits, the normative documents on ensuring safe mining conditions [17] use the follow relation:

$$
L_{i}=0.1525 E_{i}^{0.3635}
$$

where $L_{i}$ - length of discontinuity, $E_{i}$ - amount of energy.

However, it is necessary to keep in mind that by now there are no reliable data on the part of seismic energy radiated in the total energy of a seismic focal point accumulated by the time of failure. Researchers differ in their estimates of this part and take values from 0.01 to 0.1 . It follows that the total value of the energy accumulated in the failure focal point will be one or two orders of magnitude higher by the time of failure.

Table 2 shows the calculated values of the energy radiated from the failure focal points by the structural discontinuities of different linear sizes and, correspondingly, of different ranks in comparison with the classes of rock bursts according to their energy classification. Also the table shows the values of the accumulated specific energy by the time of rock failure. 
Table 2 Calculated values of elastic energy in the dynamic failure focal points in the rock mass (for the conditions of apatite-nepheline deposits of the Kola Peninsula)

\begin{tabular}{|c|c|c|c|}
\hline $\begin{array}{c}\text { Linear size of discontinuity, } \mathbf{m} \\
\text { (Character of structure } \\
\text { discontinuities) }\end{array}$ & $\begin{array}{c}\text { Radiated } \\
\text { energy, J }\end{array}$ & $\begin{array}{c}\text { Class of dynamic rock } \\
\text { pressure occurrences }\end{array}$ & $\begin{array}{c}\text { Specific energy } \\
\text { accumulated in the } \\
\text { rock mass by the } \\
\text { time of failure, } \\
\mathbf{J} / \mathbf{m}^{3}\end{array}$ \\
\hline 0.001 (contacts of mineral grains) & $10^{-6}$ & None & $10^{5}$ \\
\hline 0.01 (micro-fracturing) & $510^{-4}$ & Slabbing & $510^{4}$ \\
\hline 0.1 (small-block fracturing) & $310^{-1}$ & Spalling & $310^{4}$ \\
\hline 1 (large-block fracturing) & $210^{2}$ & Micro rock bursts & $210^{4}$ \\
\hline 10 (small-scale fractures) & $10^{5}$ & Micro rock bursts & $10^{4}$ \\
\hline 100 (large-scale fractures) & $610^{7}$ & Rock bursts & $610^{3}$ \\
\hline 1000 (small faults) & $310^{10}$ & Tectonic rock bursts & $310^{3}$ \\
\hline 10000 (medium faults) & $210^{13}$ & $\begin{array}{c}\text { Catastrophic tectonic } \\
\text { rock bursts (mining- } \\
\text { induced earthquakes) }\end{array}$ & $210^{3}$ \\
\hline
\end{tabular}

The data in Table 2 show the increase in a value of the seismic energy released with the increase in the size of discontinuities. In contrast, the value of the specific energy accumulated by the rock mass at the time of failure decreases. This fact once again confirms the primary failure on the smallest structural discontinuities.

As is known, the heterogeneity of the stress field is characterized by tangential components of the general stress tensor. So the transition to the analysis of the distribution of the principal tangential stresses is appropriate to predict the places of probable dynamic rock pressure occurrences. As threshold values above which a dynamic failure can occur in the rock mass, at the first step it is possible to take the shear strength defined for the different ranks of structural discontinuities. In particular, for structural discontinuities of the highest orders, i.e. at the level of contacts of mineral grains and micro-fracturing, as a threshold value it is possible to take the shear strength $\left[\tau_{s}\right]$ established when testing the small volumes of rocks (standard samples). Then the condition for occurrence of initial dynamic forms of rock failures will be presented as:

$$
\tau_{\max }>\left[\tau_{s}\right]
$$

where $\tau_{\max }$ - the value of the maximum main tangential stress in the rock mass, $\left[\tau_{\mathrm{s}}\right]-$ shear strength of the rocks.

However, it is more preferable to determine the conditions of dynamic rock failure by comparing the values of specific strain energy in the rock mass, based on the defined components of the stress fields and their hierarchy, with the values of specific failure energy established from the tests of rocks that compose the studied rock mass. In this case the failure conditions will be determined by the relation:

$$
\begin{gathered}
E_{d e f}>W r \\
E_{\text {def }}=\sigma_{u c s}^{2} /(2 E)
\end{gathered}
$$

where E - modulus of elasticity; $\sigma_{\text {ucs }}$ - unconfined compressive strength; $\mathrm{Wr}$ is determined by (1), i.e. by laboratory tests of the rocks composing the rock mass.

\section{The ways to solve the problem of prediction of dynamic failures}

The discussion above allows setting out the sequence for carrying out the separate working stages (to offer a sort of "road map") and estimating a modern level of methodical 
development of the allocated stages. This, in turn, allows finding a solution on the whole problem of rock bursts in mining works.

The first stage should always be the detailed zoning of the deposit studied with the specification of hierarchy of structural blocks composed the rock mass. At that the initial information is the geological study data of rocks composing the rock mass and the study results of regularities of structure discontinuity distribution of different ranks appropriated for the rock mass.

The questions of obtaining the initial information are methodically enough studied and do not cause difficulties for the specialists of the geological service of enterprises. However, mine geologists generally do not perform zoning because this is not yet part of their responsibility to support mining operations. As a result, the geomechanical specialists need to generalize geological information themselves in order to create a picture of detailed zoning of the rock mass studied.

The second stage should consist in the study of rock deformability separately for each selected hierarchical structural element of the studied rock mass in accordance with the above methodological approach - the analysis of deformation patterns at different parameters of volumetric (triaxial) loading.

It may prove to be that the individual structural blocks are composed of rocks that are unable to accumulate energy during deformation. Therefore, the blocks do not pose a threat in terms of a probable dynamic failure and, consequently, in terms of rock bursts. Such blocks can be excluded from the further consideration.

The third stage should consist of a detailed study of the natural stress fields in all of the selected structural blocks and with taking into account possible changes in the parameters of the fields, as mining operations progress.

This part of work is not methodologically well developed because by now it is possible to directly measure the parameters of effective stresses (in particular, using different doorstopper and overcoring methods) only for the rank of point fields.

Some hopes for the direct measurement of the parameters of individual and maybe even local stress fields are inspired by using of hydraulic fracturing methods. However, there is still a lot of work to be done to develop measurement techniques for high-strength rock conditions.

To determine the parameters of the natural stress fields of lower ranks - regional and, especially, global, no correct methodological approaches have been developed yet. The absence of such approaches is the main reason for unsuccessful attempts to predict earthquakes. Apparently, the solution of these problems will be connected with the use of geophysical methods.

The problems of changing the parameters of the natural stress fields under the influence of mining works are very successfully solved with the use of mathematical modeling (in particular, by the finite element method). But there everything is determined by the degree of adequacy of the accepted values of boundary conditions to the real values of the stress field parameters of the rock mass studied.

The fourth stage is to generalize all the results of the previous stages and to determine the conditions and places of a probable failure in the rock mass studied by comparing the strength (4) or energy (5) criteria of failure. Also this stage includes the development of forecast "maps of dynamic failure" with the corresponding purpose of anti-rock bursts measures in certain hazardous areas of the rock mass and at a certain time.

\section{Conclusions}

It seems that the implementation of the above approach is a rather long process (within one or several decades). But other directions right now are not found. So only on this way 
we can develop the method of scientific forecasting of such dangerous phenomena as rock bursts (and, in general, earthquakes) as an alternative to previous and modern attempts to create methods of dynamic failure prediction based on the processing of statistical data of already occurred events.

The paper has been reported at the 1-st Conference "Problems of Geomechanics of Highly Compressed Rock \& Rock Massifs".

\section{References}

1. Hast N. The measurement of rock pressure in mines. Sveriges Geologiska Undersokning, 560 (1958)

2. Markov G.A. Tectonic stress and rock pressure in the Khibiny mines. L.: Science, (1977)

3. Baron L.I. The rock strength coefficients. M.: "Science", (1972)

4. Petukhov I.M., Linkov A.M. Mechanics of rock bursts and rock bumps. M.: Nedra, (1983)

5. Cai M. Prediction and prevention of rockburst in metal mines - A case study of Sanshandao gold mine. J. Rock Mech. and Geotech. Eng., 8 (2016)

6. Kozyrev A.A., Kasparyan E.V., Fedotova Iu.V., Kuznetcov N.N. Estimating the rockburst hazard of hard rocks based on laboratory test results. Vestnik of MSTU. 22(1) (2019)

7. Kozyrev A.A., Kasparyan E.V., Savchenko S.N., Fedotova Iu.V. Regularities of mining-induced seismicity occurrences in the hierarchical-blocked rock masses. Proceeding of the Scientific-practical conference, 06-11 August, 2012. Norilsk (2012)

8. Heim A. Mechanismus der Gebirgsbildung im Anschluss an die geologische Topographie der Toedi-Windgaellen-Gruppe, Bale, (1878)

9. Kozyrev A.A., Savchenko S.N., Maltsev V.A. Development of methodological principles for the diagnostics of tectonic stresses in the upper part of the Earth's crust in order to control the dynamic rock pressure. Apatity. (1994)

10. Rasskazov I.Yu. Control and management of mining pressure in the mines of the eastern region. M.: Gornaya Kniga Publishing House (2008)

11. Panzhin A.A., Sashurin A.D. The mechanism of different scale emergency situations formation due to modern geodynamic movements. Ferrous metallurgy, 1 (2017)

12. Sashurin A.D., Balek A.E., Panzhin A.A., Usanov S.V. Innovative technology for diagnosing geodynamic activity of the geological environment and assessing the safety of subsoil use objects. Gornyi Zhurnal, 12 (2017)

13. Oparin V.N. Pendulum-type waves and geomechanical waveguides. Modern Problems of Continuum Mechanics, 13 (2011)

14. Fedotova Iu.V., Kasparyan E.V., Kuznetcov N.N. Influence of active faults on the stress state of heterogeneous rock mass. Trigger effects in geosystems, 6-9 June, 2017. - M.: GEOS (2017)

15. Riznichenko Yu.V. The dimensions of an earthquake source and a seismic moment. Studies in the physics of earthquakes. M.: Science (1976)

16. Kasakhara K. Earthquake mechanics. M.: Mir (1985)

17. Seismicity in mining. Edited by Acad. N.N. Melnikov. Apatity: Publishing House KSC RAS (2002) 